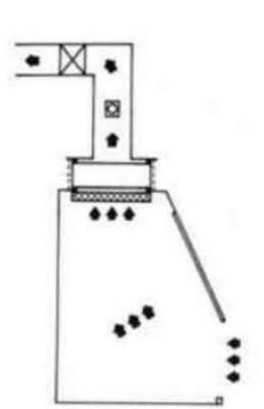

CLASS I
$10-20 \%$ air extract

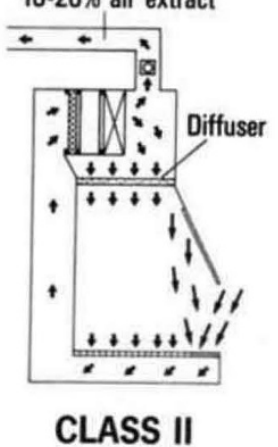

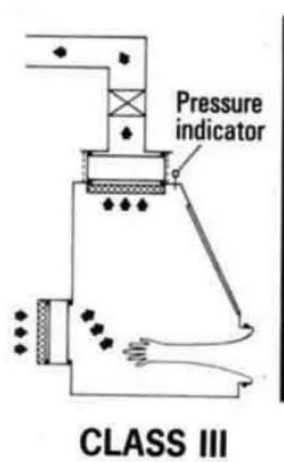
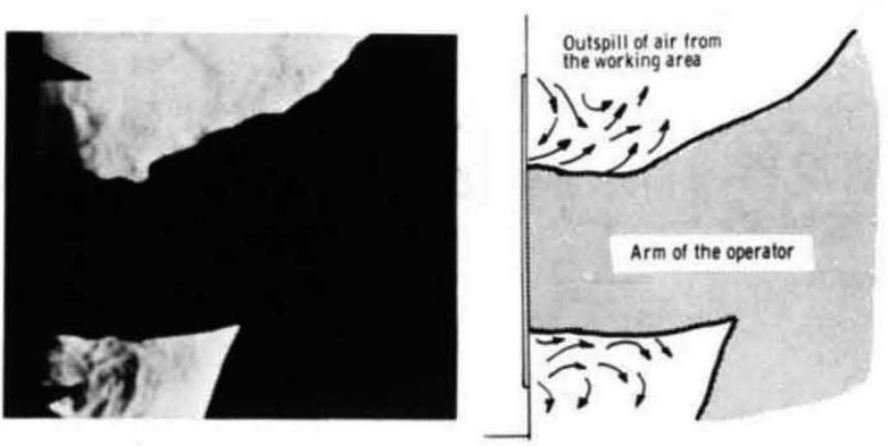

\title{
'Safety' cabinets are not safe, says UK study
}

Some of the most popular makes of safety cabinet used for biological research in the UK have containment factors 1000 times lower than the new British Standard, writes Judy Redfearn.

WORK sponsored by the UK Medical Research Council has shown that the vast majority of 'safety' cabinets currently being used for microbiological work in hospitals, universities, and research establishments throughout the UK offer so little protection to those working with them that the term safety cabinet is a misnomer. An important and positive outcome of this work, however, has been the preparation of the first British Standard (BS 5726) for safety cabinets, which is due for publication "any time now". The standard will define three classes of cabinet (see figure) and recommend minimum containment levels for each.

The cabinets which are causing most concern have a linear downflow of air at the opening. Of the dozen or so makes of this type (class II) currently available in the UK, only two, the UKmanufactured Howarth and the Italian Gelaire, have been found to come up to the new BS recommendation for containment.

Some popular makes of cabinet to have containment factors up to 1,000 times less than the recommended minimum. According to Dr R. P. Clark of the Clinical Research Centre, Harrow who has done much of the work for the MRC, in some cases and for some uses a microbiological worker could be at greater risk when using a cabinet than when working on the open bench-because the air flow created by the cabinet could cause infectious material to be blown directly at his or her face.

Class II cabinets are very popular for work where total containment is not thought necessary, because they are had been thought to offer some protection both to the worker (from inhaling infectious particles) and to the work (from contamination from the environment). The latter can be important during work with tissue cultures.

The cabinets operate by drawing air through the front opening and down through a grille in the floor. The air then moves behind the cabinet and through high efficiency filters before reentering the cabinet through the roof. During normal operation, about 80 $90 \%$ of the air is recirculated back into the cabinet and the remaining 10-20\% is filtered and discharged to the atmosphere. Drs Clark and B. J. Mullan used Schlieren photography to look at the air flow in and around cabinets running with and without an operator. They also examined the effect on the air flow of a person walking past the front of the cabinet or of a door opening and closing near it, of talking or coughing towards the cabinet and of a lighted Bunsen burner inside it. Behaviour of the air flow was also examined after switching the cabinet off.

For all the cabinets tested they found that in the first $3 \mathrm{~s}$ after switch-on a "large rolling eddy" of air spilled out of the front opening. The flow pattern then settled down and a substantial bulge of air began to circulate regularly outside the cabinet. Some air was convected away from the bulge to mingle generally with the air of the room.

The effect of an operator working with the cabinet was to cause turbulence in the air bulge outside. When a smoke pellet was ignited in the cabinet, smoke was clearly seen emerging through the front opening above the operator's hands and moving towards the face. The effect of someone coughing or speaking towards the cabinet or walking past the front of it, or of a door opening and closing near it, was to disturb the air bulge and cause it to mingle with the air in the room. After the air flow through the cabinet was switched off, the warm air inside moved upwards and outwards from the front opening and continued to do so for $10-20 \mathrm{~min}$.

Drs Clark and Mullan have tried to quantify these disturbing observations by measuring the containment of various makes of cabinet. They created an aerosol of potassium iodide solution inside each one and measured the number of droplets contained per unit volume of air just outside the front opening. They then performed the same experiment on the open bench and calculated the ratio of the measurement made on the open bench to that made with the cabinet.

This work is the basis of the new British standard. The standard will recommend that Class II cabinets (with a dummy arm inserted in the front opening) offer $10^{5}$ times more protection to the operator than the open bench.

When tests first started at the Clinical Research Centre no UK-manufactured cabinets came up to this specification and some had containment factors of only $10^{2}$. In the light of this work, however, one UK manufacturer has designed a new cabinet, the Howarth, which meets the BS specification. The cost of this model compares well, according to Dr Clark, with the cost of other less adequate cabinets. However it is disturbing, says $\mathrm{Dr}$ Clark, that some manufacturers are now rushing to sell off their old stock. He is aware of two firms taking orders in the last two weeks and threatening cancellation charges if the orders are withdrawn when the standard is announced.

But if-against this trend-the publication of BS 5726 goes hand in hand with a willingness of other manufacturers to substitute better designs, then the biologists will at least have started to tackle their major safety problem. Fume cupboards for chemical work, however, are likely to remain without a British Standard for some years yet.

Figure: cabinets in Class I (left) are designed to protect the worker but not the work. Those in Class II (second left) are for protecting both the worker and the work-as are those in Class III (centre). The latter are for work with highly infectious or pathogenic. organisms where total containment is needed. Right: what happens when an operator disturbs the air curtain in Class II cabinet. 